Research Article

\title{
Strength and Microstructural Investigation of Quaternary Blended High-Strength Concrete
}

\author{
Ayele Bereda $(\mathbb{D})$ and Belachew Asteray \\ Construction Technology and Management Stream, Department of Civil Engineering, \\ College of Architecture and Civil Engineering, Addis Ababa Science and Technology University, Addis Ababa 16417, Ethiopia
}

Correspondence should be addressed to Ayele Bereda; tesfayeayele496@gmail.com

Received 1 June 2021; Revised 16 September 2021; Accepted 25 October 2021; Published 8 November 2021

Academic Editor: Peerapong Jitsangiam

Copyright (c) 2021 Ayele Bereda and Belachew Asteray. This is an open access article distributed under the Creative Commons Attribution License, which permits unrestricted use, distribution, and reproduction in any medium, provided the original work is properly cited.

\begin{abstract}
This research focuses on studying the effect of different supplementary cementitious materials (SCMs) such as waste ceramic powder (WCP), lime powder (LP), and ground granulated blast furnace slag (GGBS) in combination on strength characteristics and microstructure of quaternary blended high-strength concrete. To achieve the aims of the study, necessary physical and chemical composition tests were done for the raw materials. Then, mixes were designed into control mix with $100 \%$ Ordinary Portland Cement (OPC) and experimental mixes containing 30\%, 40\%, 50\%, and 60\% of GGBS, WCP, and LP in combination. Tests were conducted during casting and at curing ages of 7 and 28 days. Accordingly, the control mix which is concrete grade 50 (C-50) as per American Concrete Institute (ACI) mix design is used as a reference for comparison of test results with those specimens produced by partial replacement of SCMs. The characterizations of high-strength concrete are done using consistency, setting time, workability, compressive strength, flexural strength, and morphological tests. The optimum percentage replacement is $50 \%$ OPC replacement by $30 \%$ GGBS $+10 \% \mathrm{WCP}+10 \% \mathrm{LP}$. Based on the experimental investigations, the workability increases as the replacement level of SCMs increases from $30 \%$ to $60 \%$ by weight. Compressive strength and flexural strength results increase up to $11.41 \%$ and $20 \%$ when the percentage replacement increases from $30 \%$ to $50 \%$ of SCMs replacement at 28 days of curing time, respectively. There are also improvement in the microstructure and significant cost saving due to replacing OPC partially with SCMs with proportions mentioned above. Therefore, the practice of utilizing increased percentage of SCMs in quaternary blend in concrete can be beneficial for the construction industry and sustainability without compromising the quality of the concrete product.
\end{abstract}

\section{Introduction}

Concrete is the most widely used building material worldwide due to its versatility and adaptability for different architectural purposes. For many years, concrete has been playing a great and irreplaceable role in housing and infrastructure development. Even though the evolution of material technology has been boosted since the first decade of the 21st century, on the current status of advancement and technology, there is no ideal material that can replace concrete to meet the demand for housing and infrastructure [1-3].

Regardless, concrete has an immediate association of draining natural resources and ceaseless arrival of $\mathrm{CO}_{2}$ with the climate in the creation procedure using Ordinary
Portland Cement (OPC). For each ton of concrete delivered, one ton of $\mathrm{CO}_{2}$ is discharged to the air [4]. The concrete business alone is liable for $5-8 \%$ of the worldwide man-made $\mathrm{CO}_{2}$ outflows [5-7]. By 2030, it is evaluated that concrete creation will reach as much as four billion tons every year $[6,8]$. It is not so troublesome to imagine the environment facing a challenge with cement production. As a result of such ceaseless ecological issues, endeavours have been made for quite a while and will proceed with the manageability of the Earth by utilizing elective materials or reusing distinctive industrial and agricultural wastes. Most common blending materials for concrete production are wastes from the industry or agriculture. This is because using such wastes has not only an environmental advantage but also an advantage 
from an economic and technical point of view. The environmental advantage is the reduction of $\mathrm{CO}_{2}$ emission and using the waste from dumping to landfill, while the technical advantage is an improvement in the performance of concrete and the economic advantage is replacing expensive and scarce resources with cheap and locally available material. As a result, the concept of green concrete was initiated at the end of the last century which targets replacing the ingredients of concrete partially or fully by waste or recycling materials. There are different by-products which were studied previously such as fly ash (FA), ground granulated blast furnace slag (GGBS), silica fume (SF), limestone powder (LP), waste ceramic powder (WCP), and rice husk ash (RHA) about their compatibility to be used in place of cement for concrete production attributed to their reactivity nature called pozzolanic behavior, and some are used as an inert filler $[9,10]$.

Ground granulated blast furnace slag (GGBS) is a product obtained during the creation of iron in the blast furnace. A blast furnace is taken care of cautiously with controlled blends of iron metal, coke, and limestone, at a temperature of about $2000^{\circ} \mathrm{C}$. The iron metal is diminished to iron and sinks to the base of the heater. The remaining material that stays on top is the slag. The slag is quickly extinguished using enormous volumes of water. This procedure of extinguishing upgrades the cementitious properties and produces granules like coarse sand particles. The granulated slag is dried and ground to a fine powder that is called GGBS $[11,12]$.

Ceramic is an item produced using diverse materials like mud, feldspar, quartz, dolomite, potash, and various synthetic substances like sodium silicate and sodium tripolyphosphate, blended, shaped, dried, and consumed at a temperature which changes from $200^{\circ} \mathrm{C}$ to $2000^{\circ} \mathrm{C}$. This temperature provides the material with the pozzolanic property. Waste ceramic powder (WCP) is portrayed by its compound piece that is for the most part made out of silica $\left(\mathrm{SiO}_{2}\right)$ and alumina $\left(\mathrm{Al}_{2} \mathrm{O}_{3}\right)$. The two minerals total to over $80 \%$ of the WCP piece. WCP has possibilities to be utilized as a fixing material to partially or totally supplant Portland concrete to make eco-accommodating types of cement $[13,14]$.

Lime powder (LP) comprises shifting extents of compounds, for example, calcium carbonate $\left(\mathrm{CaCO}_{3}\right)$, magnesium carbonate $\left(\mathrm{MgCO}_{3}\right)$, silica $\left(\mathrm{SiO}_{2}\right)$, alumina $\left(\mathrm{Al}_{2} \mathrm{O}_{3}\right)$, iron oxide $\left(\mathrm{Fe}_{2} \mathrm{O}_{3}\right)$, sulfate $\left(\mathrm{SO}_{3}\right)$, and phosphate $\left(\mathrm{P}_{2} \mathrm{O}_{5}\right)$, with calcium and magnesium carbonate being the two significant parts. Limestone is the most widely recognized type of calcium carbonate which is utilized broadly for the production of concrete. Concrete in various sorts is made for the most part by calcining a blend of about $75 \%$ limestone and $25 \%$ clay to frame a calcium silicate clinker which is then ground and blended with a modest quantity of gypsum [15]. There are various types of cement in which these byproducts can be applied. One of the types of cement in which these by-products of businesses can be used is high-strength concrete (HSC).

High-strength concrete is the concrete with a compressive strength of more than $42 \mathrm{~N} / \mathrm{mm}^{2}$ at 28 days of curing time. High-strength concrete is the concrete chosen to fit for the reason for which it is required. Improved properties of high-strength concrete are because of alteration of the microstructure of the high-strength concrete. The alteration in the microstructure of high-strength concrete is for the most part reliant on the response instrument among the elements of type of concrete, physical procedure, and restoring. Compound and mineral admixtures increase the response component [16-18].

The utilization of high-strength concrete for basic applications has developed significantly. The research done so far demonstrates great and positive outcomes to using industrial and agricultural wastes as cement replacement in high-strength concrete with the suggested proportion. Since some of the by-products have drawbacks we need to overcome, it is better to use ternary and quaternary mixtures to get the benefit out of each by-product and to defeat singular restrictions lately [2]. The rationale for this study emerges from the fact that the wastes that are used in this research are different in their composition, mineralogical contents, and other physical characteristics from wastes in other countries. On the other hand, the combined effect of waste ceramic powder (WCP), lime powder (LP), and ground granulated blast furnace slag (GGBS) is left open for investigation since quaternary concrete is one of the new research areas in concrete. Therefore, the objective of this study is to determine the strength and microstructural investigation of quaternary blended high-strength concrete made with waste ceramic powder, lime powder, and ground granulated blast furnace slag. Built environment sustainability is based on the principle of life cycle costing (LCC), resource conservation (RC), and human-friendly designs (HFD). In resource conservation, the $3 \mathrm{R}$ rule (reduce, reuse, and recycle) is common in construction projects and manufacturing sectors [17].

The United Nations (UN) established sustainable development goals (SDGs) also known as global goals in 2015, and these were adopted by all UN member states as a universal call to end poverty, protect the planet, and ensure the wellbeing of humans all over the world. The SDGs comprises 17 goals and 169 targets to facilitate the socioeconomic and environmental advantages of a human being. SDG goal 9 states about industry, innovation, and infrastructure which is directly related to increasing the performance of the existing infrastructure and building a new one mainly in developing and least developing countries [19]. Thus, the cement creation will expand exponentially to fulfil the need for infrastructure performance which is responsible for increasing ozone-depleting substance emanations to come. To guarantee a practical domain and financial turn of events, Ethiopia proposed taking a shot at millennium development goals (MDGs) since 2007. The MDGs involve 8 goals. The MDG objective 7 is tied in with guaranteeing ecological manageability through coordinating the standards of supportable improvement in the nation approaches and projects and contradicting the loss of natural assets [20]. Reducing greenhouse gas emissions is one of the measures to be taken for the sustainability of the environment. According to the Concrete Center (2010a, b, c), the amount of embodied $\mathrm{CO}_{2}\left(\mathrm{ECO}_{2}\right)$ incorporated in the 
concrete is a function of the cement content in the mix design. The $\mathrm{ECO}_{2}$ impact of concrete is approximately $100 \mathrm{~kg}$ carbon dioxide per ton. For sustainable concrete buildings, the embodied $\mathrm{CO}_{2}$ content of concrete is taken into account. From the perspective of $\mathrm{ECO}_{2}$, Portland Cement is the main component of concrete production. During the production of Portland Cement, a large amount of $\mathrm{CO}_{2}$ is produced. In order to reduce the carbon dioxide incorporated in concrete, Portland Cement can be partially replaced with supplementary cementing materials (SCMs), such as ground granulated blast furnace slag, waste ceramic powder, lime powder, fly ash, rice husk ash, and silica fume. In the past few decades, SCM has been widely used in the production of concrete. Most of the use of SCM is driven by to offset the cost of producing concrete and reduce construction cost. But, a more important consideration for using SCM is the sustainability dimension of concrete, because with the increase in using SCMs, we expect to substantially reduce carbon dioxide emissions, thereby reducing the impact of it on the environment [12].

Hence, to meet the goals set by the UN and Ethiopia simultaneously which means to develop infrastructure as well as to preserve the environment from greenhouse gas, it is better to use supplementary cementitious materials (SCMs). SCMs are materials possessing little or no cementitious property, but in the presence of water, the reaction with alkalis of cement forms compounds having cementitious property. Concrete is one of the environmental-friendly products but the problem is the use of Portland Cement. Hence, the green production of concrete should be based on producing much concrete with less Portland Cement. This can be achieved through the use of supplementary cementitious materials [4]. Nowadays, supplementary cementitious materials are widely applicable by either blending with cement or adding separately in a concrete mixer $[5,21,22]$. Several studies were done on different SCMs such as GGBS, fly ash, silica fume, limestone powder, ceramic powder, rice husk ash, and others as partial cement replacement individually (binary blended); combined effect of two SCMs together (ternary blended) on concrete performance was studied [2]. In recent years, a more advanced blended type called quaternary blended cement is under investigation such that the combined effect of three SCMs on concrete performance has been studied. Quaternary concrete ought to be the best substitute for Ordinary Portland Cement (OPC). The logic behind developing ternary and quaternary types of cements is to engineer mixes in which the various mineral admixtures combine to provide customized properties by compensating for their mutual drawbacks.

Until recent years, much attention has been paid to compressive strength of concrete. Mechanical strength does not show the overall average property of the concrete, and it depends on defects. However, in recent years, much of the concrete in infrastructure around the world has been deteriorating faster than expected due to the ingress of chloride ion and other ions and corrosion of reinforcement which leads researchers to pay attention to the microstructure of the concrete [7].
Therefore, the objective of this study is strength and microstructural investigation of quaternary blended highstrength concrete containing ground granulated blast furnace slag (GGBS), limestone powder (LP), and waste ceramic powder (WCP).

\section{Materials and Methods}

The constituting materials of concrete used in the present study are OPC (42.5 grade), crushed gravel as coarse aggregates (with specific gravity 2.76 and aggregate size $10 \mathrm{~mm}-20 \mathrm{~mm}$ ), natural sand as fine aggregates (specific gravity of 2.62 and maximum size of $4.75 \mathrm{~mm}$ ) confirming to Ethiopian Standard Code of Practice (ESC.D3.201), and high-range water-reducing agent of density $1.2 \pm 0.2 \mathrm{~kg} /$ liter and conforming to ASTM C-494/C 494M. The supplementary cementitious materials, which were used as the partial replacement of OPC (42.5 grade) to quaternary mixes, are WCP, GGBS, and LP, and the relevant properties of these materials were determined in the laboratory as per relevant codes of practice. Overall 45 concrete specimens were casted with each batch comprising 30 cube specimens of size $150 \times 150 \times 150 \mathrm{~mm}$ for static compressive strength tests and 15 beam specimens of size $100 \times 100 \times 500 \mathrm{~mm}$ for flexural strength tests, respectively. All the specimens were demoulded after $24 \mathrm{~h}$ and cured in the water curing tank. The physical properties and chemical composition of the cement and supplementary materials, as determined from various tests conducted, are listed in Table 1.

Table 2 presents different proportions of constituents in control mix and quaternary mixes containing GGBS, WCP, and LP. The mix combinations incorporating supplementary materials were prepared by replacing $30 \%$ to $60 \%$ of OPC by weight with these additions in quaternary mode. The percentage replacements are based on optimum values in different works of the literature and modified for the suitability of this study $[2,23,24]$.

Consistency, setting time, and slump values were measured to check the uniformity of the mixture, to determine the time required for the mixture to set, and to calculate workability of the concrete as per ACI standards for the control and experimental group.

Compressive strength was measured as per ACI standards with a $3000 \mathrm{kN}$-capacity universal testing machine using standard $150 \times 150 \times 150 \mathrm{~mm}$ cubes. The load was applied at the rate of $5.1 \mathrm{kN} / \mathrm{s}$ approximately. The average of three specimens was taken as the representative value of compressive strength of each batch of concrete.

Flexure strength was measured using standard $100 \times 100 \times 500 \mathrm{~mm}$ beam specimens, simply supported on an effective span of $400 \mathrm{~mm}$ and loaded at the third point after 28 days of curing. The test was carried out as per ACI standards.

SEM (scanning electron microscopy) was used to study the morphological characteristics of the concrete mix prepared from OPC, GGBS, WCP, and LP. A small amount of the finely powdered sample was kept in a vacuum oven at $105^{\circ} \mathrm{C}$ for $24 \mathrm{~h}$ for complete drying of the sample for further 
TABLe 1: Physical and chemical properties of GGBS, WCP, and LP.

\begin{tabular}{lccc}
\hline Descriptions & GGBS & WCP & LP \\
\hline Physical characteristics & & & \\
Specific gravity $\left(\mathrm{gm} / \mathrm{cm}^{3}\right)$ & 2.86 & 2.42 & \\
Fineness (\%) & 91.8 & 92.3 & \\
\hline Composition (\%) & & & \\
$\mathrm{SiO}_{2}$ & 52.76 & 69.38 & \\
$\mathrm{Al}_{2} \mathrm{O}_{3}$ & 14.67 & 22.28 & 19.36 \\
$\mathrm{Fe}_{2} \mathrm{O}_{3}$ & 14.14 & 3.58 & 4.3 \\
$\mathrm{CaO}$ & 6.14 & 1.24 & 1.74 \\
$\mathrm{MgO}$ & 1.76 & 0.58 & 40.58 \\
$\mathrm{Na}$ & 0.84 & 1.70 & 1.88 \\
$\mathrm{~K}_{2} \mathrm{O}$ & 0.46 & $<0.01$ & $<0.01$ \\
$\mathrm{MnO}$ & 9.48 & 0.06 & $<0.01$ \\
$\mathrm{P}_{2} \mathrm{O}_{5}$ & 0.09 & 0.38 & 0.1 \\
$\mathrm{TiO}_{2}$ & 0.52 & 0.36 & 0.15 \\
$\mathrm{H}_{2} \mathrm{O}$ & 0.08 & 0.04 & 0.08 \\
$\mathrm{LOI}$ & $<0.01$ & 0.36 & 31.53 \\
\hline
\end{tabular}

TABle 2: Concrete mix combinations for C-50 used in the present investigation.

\begin{tabular}{|c|c|c|c|c|c|c|c|c|c|c|}
\hline \multirow{2}{*}{ Mix } & \multirow{2}{*}{ Mix no. } & \multicolumn{9}{|c|}{ Weight of constituents in $(\mathrm{kg})$ of concrete C-50 } \\
\hline & & $\mathrm{OPC}$ & GGBS & WCP & LP & $\mathrm{SP}(\mathrm{ml})$ & Water & FA & $\mathrm{CA}$ & $W / B$ \\
\hline $100 \%$ OPC & M0 & 20 & - & - & - & 60 & 7.7 & 20.5 & 37.5 & 0.37 \\
\hline $70 \%$ OPC + 10 $\%$ GGBS + 15\% WCP + 5\% LP & M1 & 14 & 2 & 3 & 1 & 60 & 7.7 & 20.5 & 37.5 & 0.37 \\
\hline $60 \% \mathrm{OPC}+20 \% \mathrm{GGBS}+15 \% \mathrm{WCP}+5 \% \mathrm{LP}$ & M2 & 12 & 4 & 3 & 1 & 60 & 7.7 & 20.5 & 37.5 & 0.37 \\
\hline $50 \% \mathrm{OPC}+30 \% \mathrm{GGBS}+10 \% \mathrm{WCP}+10 \% \mathrm{LP}$ & M3 & 10 & 6 & 2 & 2 & 60 & 7.7 & 20.5 & 37.5 & 0.37 \\
\hline $40 \%$ OPC $+40 \%$ GGBS $+10 \% \mathrm{WCP}+10 \% \mathrm{LP}$ & M4 & 8 & 8 & 2 & 2 & 60 & 7.7 & 20.5 & 37.5 & 0.37 \\
\hline
\end{tabular}

processing. The test was conducted as per the standard procedure established by the laboratory.

\section{Results and Discussion}

3.1. Study of Consistency and Setting Time. Use of supplementary cementitious materials increases the consistency of the fresh binder pastes because an additional volume of fine samples is added to the mixtures [20]. The consistency values of different binder mixes in $\%$ are given in Figure 1. The setting time (initial and final) of the quaternary paste containing different replacement materials is also provided in Figure 1. From the results, it can be noted that in quaternary mixes, there is an increase in initial and final setting time durations. In general, the increase in the setting time may be due to the reduction in the rate of pozzolanic reaction with addition of SCMs. The highest increase in in final setting time is observed for the case of OPC (40\%) + GGBS $(40 \%)+$ WCP $(10 \%)+$ LP $(10 \%)$.

3.2. Study of Workability. Better workability of concrete is needed for the correct placing and compaction of the concrete in structural components. High workability can be accomplished by keeping up water-cement proportion or adding admixtures. Table 3 shows that the slump estimation of fresh concrete of all the blends is in the range of $86-118 \mathrm{~mm}$, which characterizes workability as high. These workability values are accomplished at a water-cement ratio of 0.37 , and a superplasticizer $(3 \mathrm{ml} / \mathrm{kg})$ of the cementitious material is added to upgrade the workability. Addition of GGBS, WCP, and LP (30\% to 60\%) improves the workability of the blend because of their fineness when compared with OPC. Furthermore, addition of GGBS, WCP, and LP also contributes to increasing the slump values, fundamentally because of high specific surface areas. The slump values of different blend proportions of quaternary concrete increase when substitution of GGBS, WCP, and LP with concrete increases from 30 to $60 \%$.

3.3. Compressive Strength Test. The averaged compressive strength results of cube specimens of each batch of different concrete cubes measured at 7 and 28 days of curing are presented in Figure 2.

It was seen that the compressive strength of all blend combinations increases constantly over the long term. Quaternary blend mixes M1, M2, and M3 have indicated the best performance among others at higher age. There is no enormous distinction in the early strength of cement because of moderate reaction in the pozzolana.

The increase in the strength of concrete containing cement additive substances is credited to the reaction of silicates of mineral additive substances with released lime to form extra C-S-H that adds to the improvement of compressive strength. M4 performance diminished because a high amount of SCMs in the blend hinders the strength advancement, which is further supported by the literature finding $[17,25]$. The literature also supports that with curing for a long time, the replacement of cement with pozzolanic 


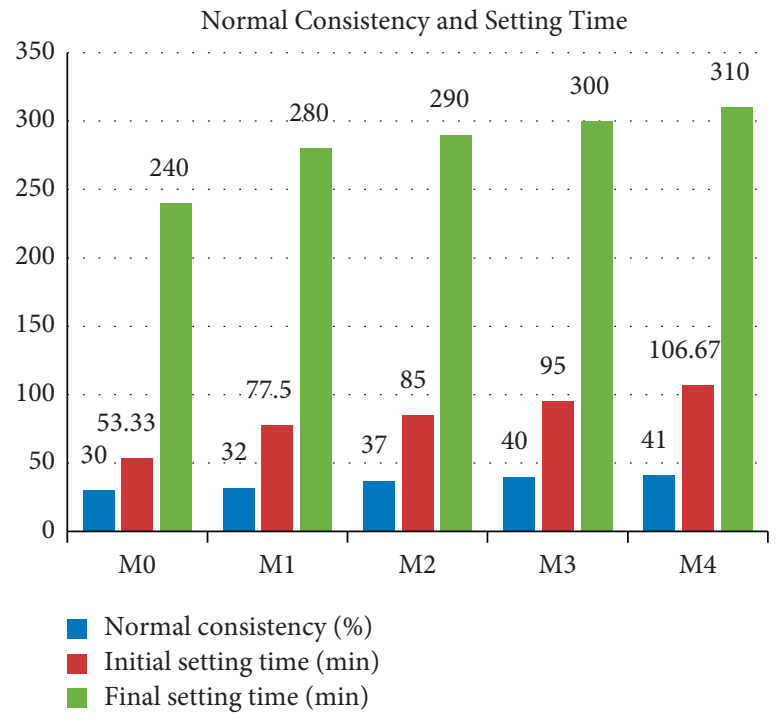

Figure 1: Normal consistency and setting time.

Table 3: Comparison of the slump test for the workability study of fresh concrete.

\begin{tabular}{lcc}
\hline Mix combinations & Mix no. & Slump (mm) \\
\hline $100 \%$ OPC & M0 & 86 \\
$70 \%$ OPC $+10 \%$ GGBS $+15 \%$ WCP $+5 \%$ LP & M1 & 92 \\
$60 \%$ OPC $+20 \%$ GGBS $+15 \%$ WCP $+5 \%$ LP & M2 & 105 \\
$50 \%$ OPC $+30 \%$ GGBS $+10 \%$ WCP $+10 \%$ LP & M3 & 110 \\
$40 \%$ OPC $+40 \%$ GGBS $+10 \%$ WCP $+10 \%$ LP & M4 & 118 \\
\hline
\end{tabular}

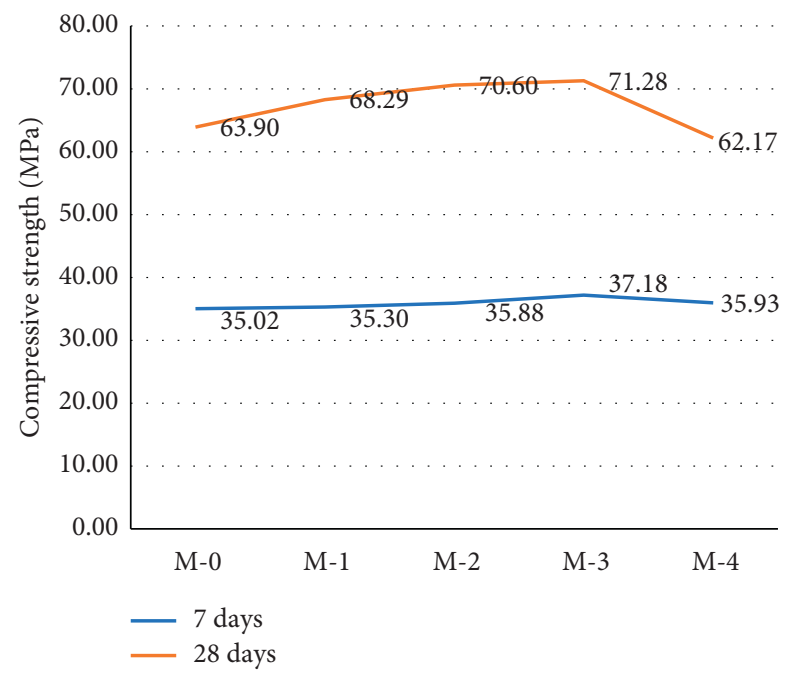

FIgURE 2: Compressive strength test result.

materials gives the best compressive strength and it is altogether higher than of the control concrete.

The best compressive strength of quaternary binder was acquired for M3 which developed a good compressive strength at 28 days.

3.4. Flexural Strength Test. Figure 3 shows the static flexural strength test results of all quaternary concrete specimens at the given test days. Quaternary blend combinations containing GGBS, WCP, and LP have showed the best performance among others at 28 days at 50\% OPC $+30 \%$ GGBS $+10 \% \mathrm{WCP}+10 \%$ LP. M2 and M3 (60\% OPC $+20 \%$ GGBS $+15 \% \quad \mathrm{WCP}+5 \% \quad \mathrm{LP} \quad$ and $50 \% \quad \mathrm{OPC}+30 \%$ GGBS $+10 \%$ WCP $+10 \%$ ) have demonstrated the best flexural strength among different mixes. It was observed that supplementary cementitious materials appeared to have articulated the impact on flexural strength. Perceptions show 


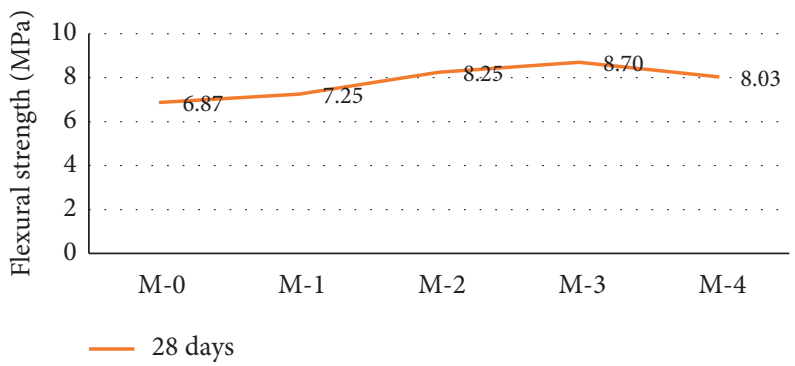

Figure 3: Flexural strength test result.

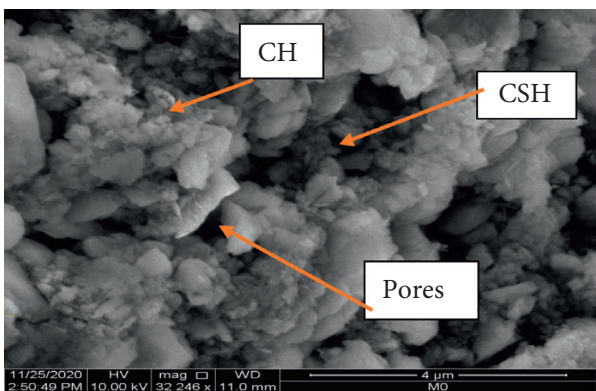

(a)

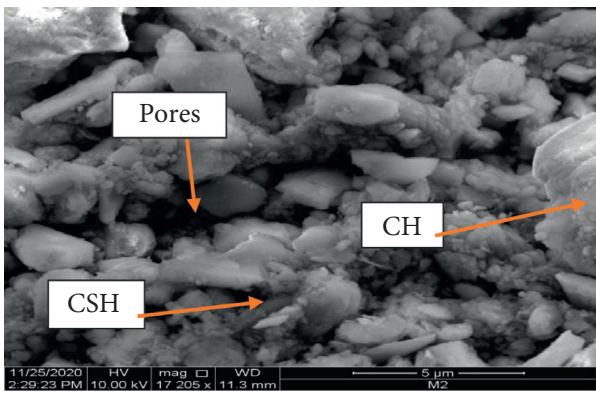

(c)

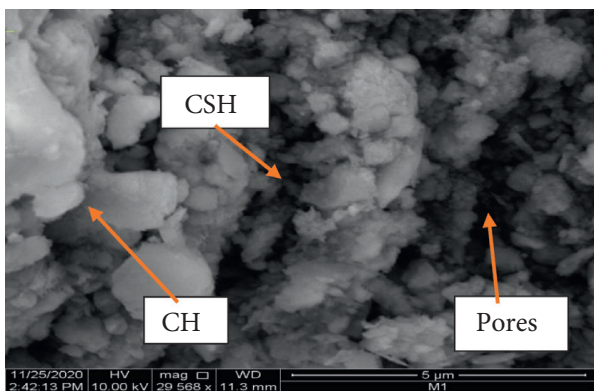

(b)

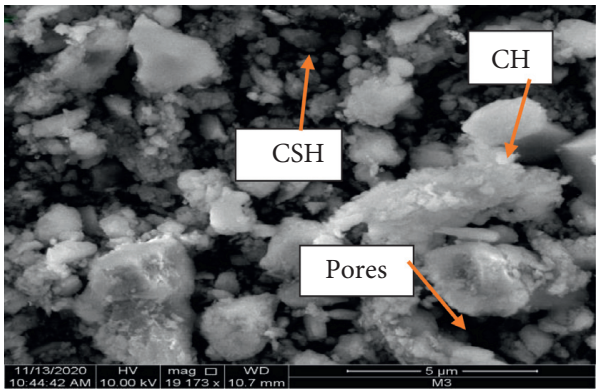

(d)

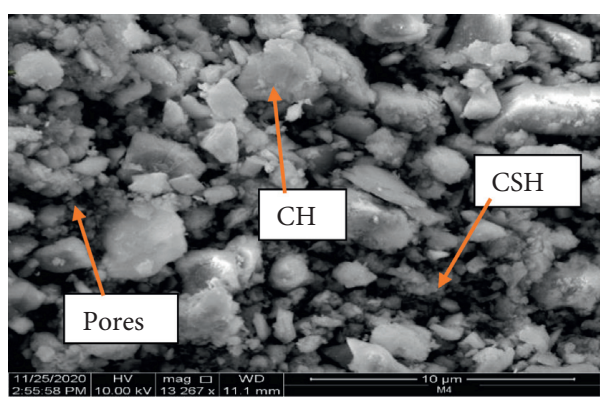

(e)

Figure 4: A SEM image of (a) 100\% Ordinary Portland Cement hydration product, (b) $70 \%$ OPC $+10 \%$ GGBS $+15 \%$ WCP $+5 \%$ LP hydration product, (c) $60 \%$ OPC $+20 \%$ GGBS $+15 \% \mathrm{WCP}+5 \%$ LP hydration product, (d) $50 \%$ OPC $+30 \%$ GGBS $+10 \% \mathrm{WCP}+10 \% \mathrm{LP}$ hydration product, and (e) $40 \%$ OPC $+40 \%$ GGBS $+10 \%$ WCP $+10 \%$ LP hydration product.

that there is a consistent increase in flexural strength with increment in the level of supplementary cementitious materials in the blend. Different blends have likewise indicated great flexural strength, the same as control.

3.5. SEM Studies. The micrograph of mixes with SCMs shows better hydrated grain at 28 days of curing time. This might be because of better packing of the replaced materials. The overall pore in the microstructure is exceptionally reduced; however, the interlocking between the hydrated grains is not so prominent. Figures 4(a) $-4(\mathrm{e})$ show the microstructure of the samples prepared with GGBS, WCP, and LP at 28 days of curing time.

The overall microstructure of the control specimen is densely precipitated, but few couple of pores are noticed. It 
has been discovered that the precipitation of $\mathrm{C}-\mathrm{S}-\mathrm{H}$ is responsible for hindering the pace of reaction since the diffusion of ions control the hydration cycle [26].

To accomplish the high-strength requirement (higher than $50 \mathrm{MPa}$ ), just diminishing the capillary porosity is not sufficient, yet additionally, a significant decrease in the complete porosity should be accomplished by lessening the gel porosity. This substantial porosity decrease is needed to change the $\mathrm{C}-\mathrm{S}-\mathrm{H}$ structure from permeable to more crystalline stage, i.e., change in concrete microstructure [27].

When added to the cement paste, pozzolanic materials play a significant role in upgrading the mechanical and durability properties. The main impact on microstructure is the adjustment in pore structure by the decrease in the grain size, which came about, chemically, from the pozzolanic reactions (pozzolanic impact) and, truly, from the obstruction of pores by the activity of the better grains (filler effect) [28].

The micrograph of M0 and M3 shows better hydrated grain at 28 days of curing time. The void spaces available in the middle of the hydrated particles are effectively recognized. The hydrated particles are all connected and associated with less number of voids. The development of these hydrated particles is responsible for the increase in strength of the concrete. The presence of finely ground pozzolanic materials like WCP, LP, and GGBS prompts the densification of the microstructure and thus results in the compressive strength increments $[23,29,30]$.

\section{Conclusions}

This study investigates the behavior of quaternary concrete after incorporating GGBS, WCP, and LP. The experimental results revealed that the addition of supplementary cementitious materials, such as, GGBS, WCP, and LP, in cement affects the properties of concrete. Based on the test results, the following conclusions can be drawn:

(1) The normal consistency, initial setting time, and final setting time of quaternary cement increase by $36.6 \%$, $100 \%$, and $29.17 \%$ as the replacement level of GGBS, WCP, and LP increases, from $0 \%$ to $60 \%$ simultaneous replacement of OPC. From this, it is implied that those SCMs show additional water demand for workability as the replacement of the SCMs increased.

(2) The results from the slump tests for the concrete, GGBS, WCP, and LP mixes show a slump increment of $37.21 \%$ as the level of the SCMs replacement increases from $0 \%$ to $60 \%$. This proves that the addition of SCMs like GGBS, WCP, and LP improves the workability of the concrete mixes.

(3) The compressive strength of quaternary blended high-strength concrete containing GGBS, WCP, and LP at different replacement levels has also been assessed. The compressive strength of experimental group mix is compared with that of control mix, and it shows higher value of compressive strength in the experimental mix than in the control mix. M3 (50\% OPC $+30 \%$ GGBS $+10 \%$ $\mathrm{WCP}+10 \% \mathrm{LP}$ ) shows $11.41 \%$ higher compressive strength than the control mix.

(4) The flexural strength of M3 (50\% OPC $+30 \%$ GGBS $+10 \% \mathrm{WCP}+10 \% \mathrm{LP}$ ) is $20 \%$ higher than of the control mix.

(5) The overall microstructure of the control specimen is densely precipitated, but few couple of pores are noticed. The presence of finely ground pozzolanic materials like WCP, LP, and GGBS prompts the densification of the microstructure and thus results in the compressive strength increase.

Therefore, incorporating supplementary cementitious materials such as GGBS, WCP, and LP in predetermined proportions in quaternary form of high-strength concrete is beneficial from the environmental, technical, and economic point of view.

\section{Data Availability}

The data used to support the findings of this study are available from the corresponding author upon request.

\section{Conflicts of Interest}

The authors declare that they have no conflicts of interest.

\section{Acknowledgments}

The authors thank the Ministry of Science and Higher Education (MoSHE) of Ethiopia for the financial support to conduct the research.

\section{References}

[1] B. Lothenbach, K. Scrivener, and R. D. Hooton, "Supplementary cementitious materials," Cement and Concrete Research, vol. 41, no. 12, pp. 1244-1256, 2011.

[2] A. Al-Mansour and C. L. L. R. D. Chow, "Green concrete: byproducts utilization and advanced approaches," Sustainability, vol. 11, no. 19, p. 5145, 2019.

[3] G. Menéndez, V. Bonavetti, and E. F. Irassar, "Strength development of ternary blended cement with limestone filler and blast-furnace slag," Cement and Concrete Composites, vol. 25, no. 1, pp. 61-67, 2003.

[4] C. meyer, "The greening of the concrete industry," Cement and Concrete Composites, vol. 31, no. 8, pp. 601-605, 2009.

[5] A. Schöler, B. Lothenbach, F. Winnefeld, and M. Zajac, "Hydration of quaternary portland cement blends containing blast-furnace slag, siliceous fly ash and limestone powder," Cement and Concrete Composites, vol. 55, pp. 374-382, 2015.

[6] H. Klee, "Briefing: The cement sustainablity initiative," in Proceedings of the Institution of Civil Engineers-Engineering Sustainability, vol. 157, no. 1, Geneva, Switzerland, March 2004.

[7] D. Bentz and P. Stutzman, "Internal Curing and Microstructure of High Performance Mortars," in Proceedings of the ACI SP-256, Internal Curing of High Performance Concretes, pp. 81-90, Laboratory and Field Experiences, Farmington Hills, MI, USA, 2008.

[8] C. Chen, G. Habert, Y. Bouzidi, and A. Jullien, "Environmental impact of cement production: detail of the different 
processes and cement plant variability evaluation," Journal of Cleaner Production, vol. 18, no. 5, pp. 478-485, 2010.

[9] R. D. Hooton, "Canadian use of ground granulated blastfurnace slag as a supplementary cementing material for enhanced performance of concrete," Canadian Journal of Civil Engineering, vol. 27, no. 4, pp. 754-760, 2000.

[10] B. Saghafi, H. Al Nageim, and W. Atherton, "Mechanical Behavior of a new base material containing high volumes of limestone waste dust, PFA, and APC residues," Journal of Materials in Civil Engineering, vol. 25, no. 4, pp. 450-461, 2013.

[11] J. M. Khatib and J. J. Hibbert, "Selected Engineering properties of concrete incorporating slag and metakaolin," Construction and Building Materials, vol. 19, no. 6, pp. 460-472, 2005.

[12] S. Samad and A. Shah, "Role of binary cement including Supplementary Cementitious Material (SCM), in production of environmentally sustainable concrete: a critical review," International journal of Sustainable built environment, vol. 6, no. 2, pp. 663-674, 2017.

[13] A. S. El-Dieb, M. R. Taha and Samir, and I. Abu-Eishah, "The use of ceramic waste powder (CWP) in making eco-friendly concretes," Ceramic Materials-Synthesis, Characterization, Applications and Recycling, IntechOpen, London, UK, 2018.

[14] A. Heidai and D. Tavakoli, "A study of the mechanical properties of ground ceramic powder concrete incorporating nano- $\mathrm{SiO}_{2}$ particles," Construction and Building Materials, vol. 38, pp. 255-264, 2013.

[15] W. Gudissa and A. Dinku, "The use of limestone powder as an alternative cement replacement material: an experimental study," EEA journal, vol. 27, pp. 33-43, 2010.

[16] A. C. E701, Cementitious Materials for ConcreteAmerican Concrete Institute, Farmington Hills, MICH, USA, 2013.

[17] G. Barmley and S. Power, "Urban form and social sustainability: the role of density and housing type," Environment and Planning B: Planning and Design, vol. 36, no. 1, pp. 30-48, 2009.

[18] T. Kibriya, "Crushed limestone waste as supplementary cementing material for high strength concrete," American Journal of Civil Engineering and Architecture, vol. 5, no. 3, pp. 93-97, 2017.

[19] UN, Critical Milestones towards Coherent, Efficient and Inclusive Follow-Up and Review at the Global Level, SecretaryGeneral, New York, NY, USA, 2016.

[20] UN, Millennium Development Goals: Ethiopia, UN, New York, NY, USA, 2007.

[21] B. E. Scheefz, M. R. Slisbee, and D. M. Roy, "Processing of optimized cements and concretes via particle packing," $M R S$ bulletin, vol. 18, no. 3, pp. 45-49, 1993.

[22] P. Duan, Z. Shui, W. Chen, and C. Shen, "Enhancing microstructure and durability of concrete from ground granulated blast furnace slag and metakaolin as cement replacement materials," Journal of Materials Research and Technology, vol. 2, no. 1, pp. 52-59, 2013.

[23] N. Dave, A. K. Misra, A. Srivastava, A. K. Sharma, and S. K. Kaushik, "Study on quaternary concrete micro-structure, strength, durability considering the influence of multi-factors," Construction and Building Materials, vol. 139, pp. 447-457, 2017.

[24] N. Dave, A. K. Misra, A. Srivastava, and S. K. Kaushik, "Experimental analysis of strength and durability properties of quaternary cement binder and mortar," Construction and Building Materials, vol. 107, pp. 117-124, 2016.
[25] A. M. Neville, Properties of concrete, Longman London, Harlow, England, 1995.

[26] D. Lau and O. Büyüköztürk, High Performance Concrete: Fundamentals and Application, Department of civil and environmental engineering, Massachusetts institute of technology, Cambridge, MA, USA.

[27] G. C. Isaia, A. L. G. Gastaldini, and R. Moraes, "Physical and pozzolanic action of mineral additions on the mechanical strength of high-performance concrete," Cement and Concrete Composites, vol. 25, no. 1, pp. 69-76, 2003.

[28] P. V. Sivapullaiah and A. K. Sharma, "Strength development in fly ash and slag mixtures with lime," in Proceedings of the Institution of Civil Engineers-Ground Improvement, Bangalore, India, July 2016.

[29] Y. Jeong, H. Park, Y. Jun, J.-H. Jeong, and J. E. Oh, "Microstructural verification of the strength performance of ternary blended cement systems with high volumes of fly ash and GGBFS," Construction and Building Materials, vol. 95, pp. 96-107, 2015.

[30] B. Espion, B. Lebon, C. Pierre, O. Germain, A. Hellebois, and K. Sakai, "Characterisation of new ternary cements with reduced clinker content," in Proceedings of the first international conference on concrete sustainability (ICCS13), Tokyo, Japan, May 2013. 